\title{
Odontoid balloon kyphoplasty associated with screw fixation for Type II fracture in 2 elderly patients
}

\author{
*Luc Terreaux, MD,, Thomas Loubersac, ${ }^{1}$ Olivier Hamel, MD, PhD, ${ }^{1}$ Eric Bord, MD, ${ }^{1}$ \\ Roger Robert, MD, PhD, ${ }^{1}$ and Kevin Buffenoir, MD, PhD ${ }^{1,2}$
}

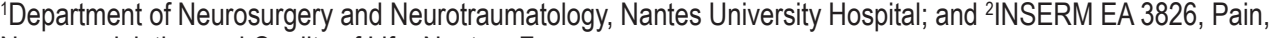
Neuromodulation and Quality of Life, Nantes, France
\end{abstract}

\begin{abstract}
Anterior screw fixation is a well-recognized technique that is used to stabilize Type IIB fractures of the odontoid process in the elderly. However, advanced age and osteoporosis are 2 risk factors for pseudarthrosis. Kyphoplasty has been described in the treatment of lytic lesions in C-2. The authors decided to combine these 2 techniques in the treatment of unstable fractures of the odontoid.

Two approximately 90-year-old patients were treated for this type of fracture. Instability was demonstrated on dynamic radiography in one patient, and the fracture was seen on static radiography in the other. Clinical parameters, pain, range of motion, 36-Item Short Form Health Survey (SF-36) score (for the first patient), and radiological examinations (CT scans and dynamic radiographs) were studied both before and after surgery.

After inflating the balloon both above and below the fracture line, the authors applied a high-viscosity polymethylmethacrylate cement. Some minor leakage of cement was noted in both cases but proved to be harmless. The screws were correctly positioned. The clinical result was excellent, both in terms of pain relief and in the fact that there was no reduction in the SF-36 score. The range of motion remained the same. A follow-up CT scan obtained 1 year later in one of the patients showed no evidence of change in the materials used, and the dynamic radiographs showed no instability.

This combination of kyphoplasty and anterior screw fixation of the odontoid seems to be an interesting technique in osteoporotic Type IIB fractures of the odontoid process in the elderly, with good results both clinically and radiologically. http://thejns.org/doi/abs/10.3171/2014.11.SPINE131013
\end{abstract}

KEY WORDS balloon kyphoplasty; elderly; odontoid fracture; odontoid screw fixation; vertebral fracture; cervical

$\mathrm{T}$ HE management of odontoid fractures in the elderly is an area of some controversy. With an increasing number of elderly individuals worldwide, we must expect an increase in this type of fracture. Indeed, the incidence of traumatic events to the cervical spine in people older than 65 years is estimated to be between 4.75 and 12.4 per 100,000 individuals per year. ${ }^{48}$ Among these traumatic events, still in elderly individuals, $68.9 \%$ affect the upper cervical spine. ${ }^{48}$ Concentrated in this latter group, the proportion in which the odontoid is affected is the most important.$^{34}$ As it happens, fractures of the odontoid are the most common unstable fractures of the upper cervical spine, with a rate estimated to be between $10 \%$ and $11 \% .^{21,35}$

These fractures happen in the elderly with a low-energy impact. ${ }^{7,48}$ This section of the population has physiological demineralization and sensory loss, and this renders them more susceptible to repeated falls with blows to the forehead, causing hyperextension of the neck.,20,33,34,48

Among these fractures of the odontoid, 4 types have been established with the aim of predicting those most at risk for instability. Most commonly used is the classification of Anderson and D'Alonzo ${ }^{2}$ from 1974. In 2005, Grauer et al. ${ }^{16}$ modified this by integrating the subclassification described by Roy-Camille et al. ${ }^{39}$ and Hadley et al. ${ }^{17}$ Type I fractures are those that pass above the inferior part of the anterior arch of C-1. Type II fractures are subdivided into Type IIA when there is no displacement, Type IIB when the fracture is sloping down backward (the OBAR equivalent described by Roy-Camille et al.), and Type IIC when

ABBREVIATIONS SF-36 $=36$-Item Short Form Health Survey; VAS $=$ visual analog scale.

SUBMITTED November 9, 2013. ACCEPTED November 6, 2014.

INCLUDE WHEN CITING Published online January 2, 2015; DOI: 10.3171/2014.11.SPINE131013.

DISCLOSURE The authors report no conflict of interest concerning the materials or methods used in this study or the findings specified in this paper.

* Drs. Terreaux and Buffenoir contributed equally to this work. 
the fracture is sloping downward anteriorly (the OBAV equivalent described by Roy-Camille et al.) or comminuted (the Type IIA equivalent described by Hadley et al.). By definition, Type III fractures pass through the body of $\mathrm{C}-2$ and to at least one superior joint facet on $\mathrm{C}-2$, which is more precise than the initial classification. Type II is the most common, the most unstable, and the one most at risk for pseudarthrosis. ${ }^{2,20,48}$ Type III is second in terms of frequency and is generally stable. Type I is stable and extremely uncommon. Grauer et al. ${ }^{16}$ have also proposed recommendations for the treatment of each subtype.

Currently, despite the emergence of prospective studies, ${ }^{22,45}$ there is no consensus regarding the treatment for Type II fractures in the elderly. ${ }^{20,33,34}$ Surgical and orthopedic treatments are regularly compared. Each is associated with a certain number of failures, morbidity, and mortality. A case-control study showed that the risk of failure by orthopedic treatment with a Halo jacket for Type II fractures was 21 times greater for patients older than 50 years. ${ }^{24}$ Posterior fixations have an increased rate of fusion, from $78 \%$ to $100 \%$, but carry a risk, notably of damage to the vertebral artery, up to $8.2 \% .{ }^{35}$ Anterior screw fixation, described by Böhler, ${ }^{6}$ is similarly a standard treatment, ${ }^{13}$ with a fusion rate of up to $90 \%$, but osteopenia and old age are 2 significant risk factors for pseudarthorsis. ${ }^{18}$

The techniques of cementoplasty and C-2 kyphoplasty have been described in another context of morbidity: lytic lesions in the body of C-2. ${ }^{14,27}$ High-viscosity polymethylmethacrylate cement can be used for such interventions under fluoroscopic guidance either transorally3,27,36,40 or by an anterolateral cervical approach. ${ }^{8,10,30,38,43,49}$ Another technique using these 2 routes has also been described, kyphoplasty, which allows for better control of the injection zone with cement by the creation of a cavity. $11,14,15,26,31$

We decided to combine the 2 techniques of anterior screw fixation of the odontoid and balloon kyphoplasty to obtain satisfactory compression and limit the chances of subsequent displacement in 2 female patients approximately 90 years of age with severe osteoporosis.

\section{Case Studies \\ Patients}

Two female patients were referred to us for management of Type IIB fractures of the odontoid peg. Both the clinical and radiological data were considered together before proceeding to surgery.

The first patient treated by this technique (Case 1) was 90 years old. She had a lengthy medical history that included inhaled steroids for asthma. She had been admitted to care because of an increasing inability to care for herself, although she was not impaired intellectually. She presented to us after a fall that was classic in that it involved a knock to her forehead causing hyperextension of her cervical spine. Before her fall, her 36-Item Short Form Health Survey (SF-36) scores ${ }^{47}$ were 38.3 for physical health (Physical Component Summary) and 38.7 for mental health (Mental Component Summary). Clinical examination was unremarkable apart from severe neck pain, rated on a visual analog scale (VAS) at 8 of 10. Radiographs and then $\mathrm{CT}$ scans of the cervical spine con- firmed the fracture of the odontoid, though with very little displacement (Type IIB). The odontoid process was weakened at its base by a multifactorial osteopenia, classified as being moderate (less than $50 \%$ lacunae in trabecular bone) according to the classification of Lakshmanan et al. ${ }^{23}$ (Fig. 1). The initial dynamic radiographs of the cervical spine, obtained at 48 hours postinjury, revealed no instability, and orthopedic treatment with a Minerva corset was chosen. As this was poorly tolerated, despite 2 adaptations, it was simplified with a rigid Minerva. Secondary complications ( 1 month after the fracture) involving the skin under the chin (Fig. 2) and destabilization of the fracture with movement of approximately $5 \mathrm{~mm}$ (Fig. 3) led to the choice of surgery. The last evaluation of this patient was 18 months after surgery, with clinical and radiology follow-up at 3,6, and 12 months.

The second patient (Case 2) was 88 years old. She was also admitted to care before her neck injury, mainly because of a cognitive disorder (the SF-36 was not administered because of this). She was considered as being in Group 2 of the Iso Resources Groupings according to the criteria established by the AGGIR grid ${ }^{46}$ but was still mobile around the establishment. Her main medical history comprised ischemic heart disease with heart failure, temporal arteritis, Alzheimer's disease, and non-insulin-dependent diabetes. The mechanism of her injury was identical to that of Case 1. Initial clinical examination likewise demonstrated only intense neck pain, and she had a VAS score of 9 . However, radiography (Fig. 4 left) followed by CT scanning (Fig. 4 right) revealed a significantly displaced Type IIB fracture with a severe osteopenia $(>50 \%$ lacunae) in the odontoid process. Surgery was immediately decided upon. Clinical and radiography follow-up were carried out 1 and 3 months later.

For these 2 patients, the prone position during surgery was contraindicated according to our anesthesiologists (due to significant comorbidities). This made $\mathrm{C} 1-2$ posterior fixation not possible. Second, the severe osteopenia of these patients significantly increased the risk of mobilization and pseudarthrosis with a single anterior screw. Our experience with the use of vertebroplasty in osteoporotic vertebral settlements has led us to propose the combination of this technique with anterior screw fixation in the 2 octogenarians.

\section{Operative Technique}

The details of the surgeries were quite different for the 2 patients, with regard to the size of the balloon and then its deployment for inflation. Under general anesthesia, the patient was placed in the dorsal decubitus position. The head was placed in the neutral position. Two image intensifiers were positioned during the operation to gain continuous monitoring face on (the mouth was kept open by a radiolucent packing) and laterally. The first stage consisted of ascertaining that reduction had been achieved via the operative position, with correction of the backward tilt of the dens and alignment of the 2 fragments of the fracture. A classic odontoid screw fixation anterolateral approach through the neck was then undertaken. An oblique incision was made over the medial border of the sternocleidomastoid muscle. The various planes were dissected out as far 

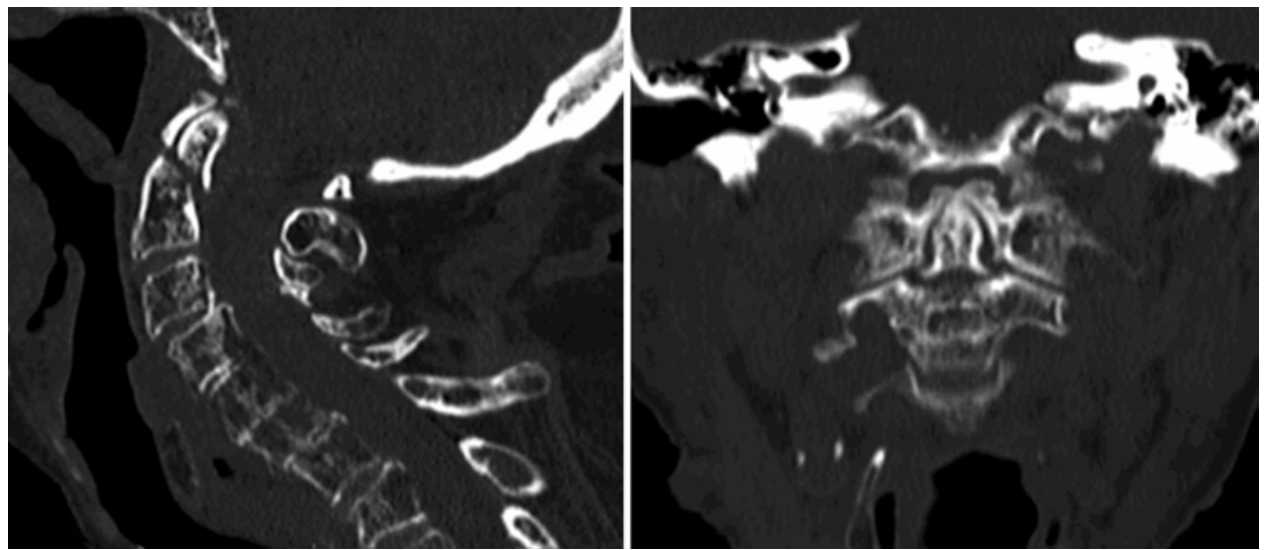

FIG. 1. Case 1. Initial sagittal (left) and coronal (right) CT scans showing a Type IIB fracture with only slight displacement (2 mm). Moderate osteopenia is present $(<50 \%$ lacunae in trabecular bone).

as the deep cervical fascia at the level of $\mathrm{C} 4-5$, the jugulocarotid bundle was retracted laterally, and the trachea/ esophagus was retracted medially. The anterior inferior border of $\mathrm{C}-2$ was reached by moving along the fascia. A guidewire was introduced with the help of a power drill as far as the upper portion of the odontoid process. An operating cannula was placed into the body of $\mathrm{C}-2$ with the aid of the guidewire. With the guidewire removed, the area was tapped out (Fig. 5A) over the length of the bony aperture and particularly toward the fracture zone. A balloon was then introduced. In Case 1, the balloon measured 10 $\mathrm{mm}$ and was progressively inflated in 3 stages under fluoroscopic control, at low pressure (150 psi), into the upper extremity of the odontoid, the base, and then the body of C-2 (Fig. 5B). For Case 2, the balloon measured $20 \mathrm{~mm}$ and was managed all in 1 stage.

The radiopaque markers could be seen above and be-

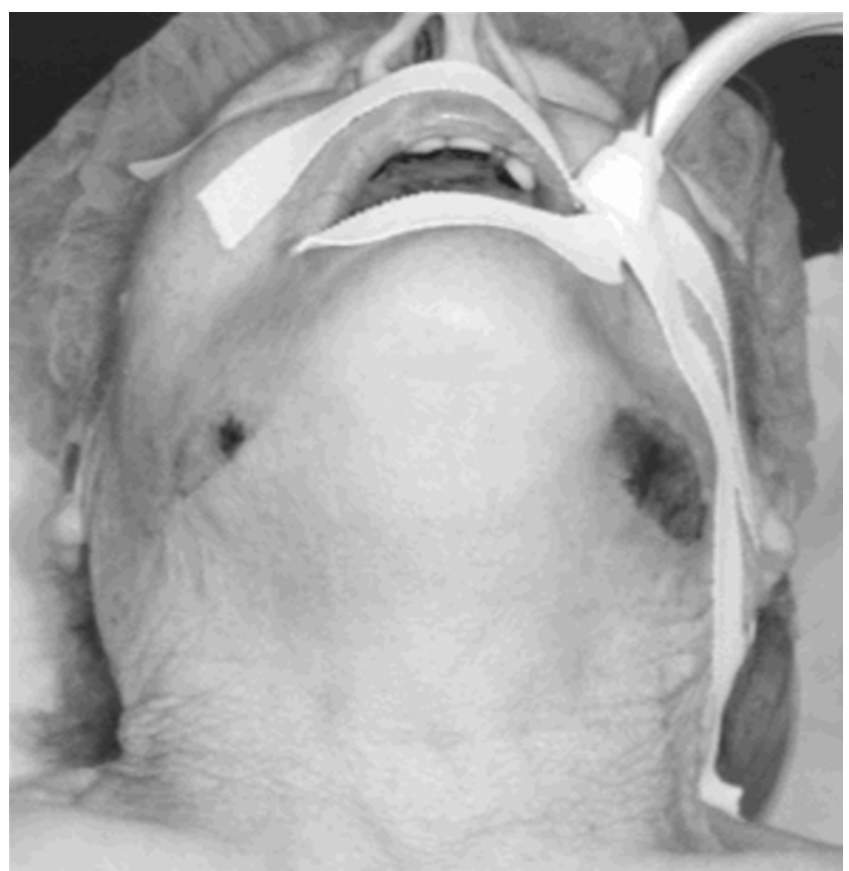

FIG. 2. Case 1. Operative position showing the submandibular ulceration. low the fracture line, and therefore just a single inflation was necessary. The volume was $2 \mathrm{ml}$ on each occasion. Once the balloon was withdrawn, the high-viscosity cement (polymethylmethacrylate) was introduced (Fig. 5C), starting at the upper portion of the odontoid. The guidewire was quickly reinserted and the operating cannula was removed to be able to orient the insertion of the Asnis screw (Stryker), the length of which had been previously determined. The screw was inserted as far as the superior endplate (Fig. 5D), thus going beyond the cemented part and ensuring that the entire threaded section was placed above the fracture site and allowed for compression onto a washer placed around the head of the screw. The guidewire was removed, and the wound was closed in layers.

\section{Results}

The duration of surgery was approximately 45 minutes in both cases. Minor cement leakage occurred in both patients, anteriorly and laterally at the level of the fracture,

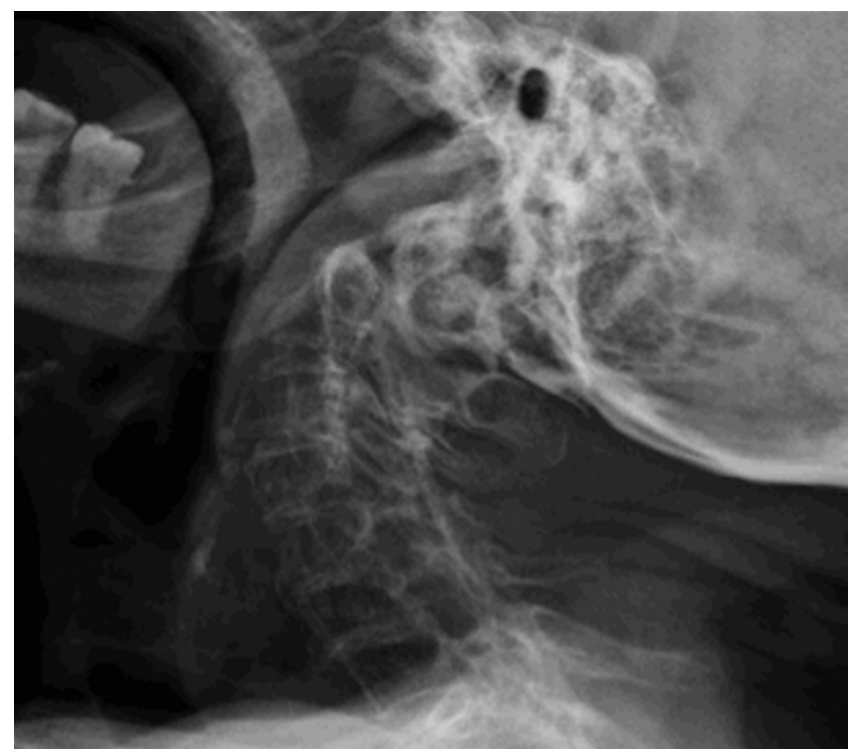

FIG. 3. Case 1. Dynamic radiograph obtained 1 month after injury with the neck extended, showing a displacement of $5 \mathrm{~mm}$. 

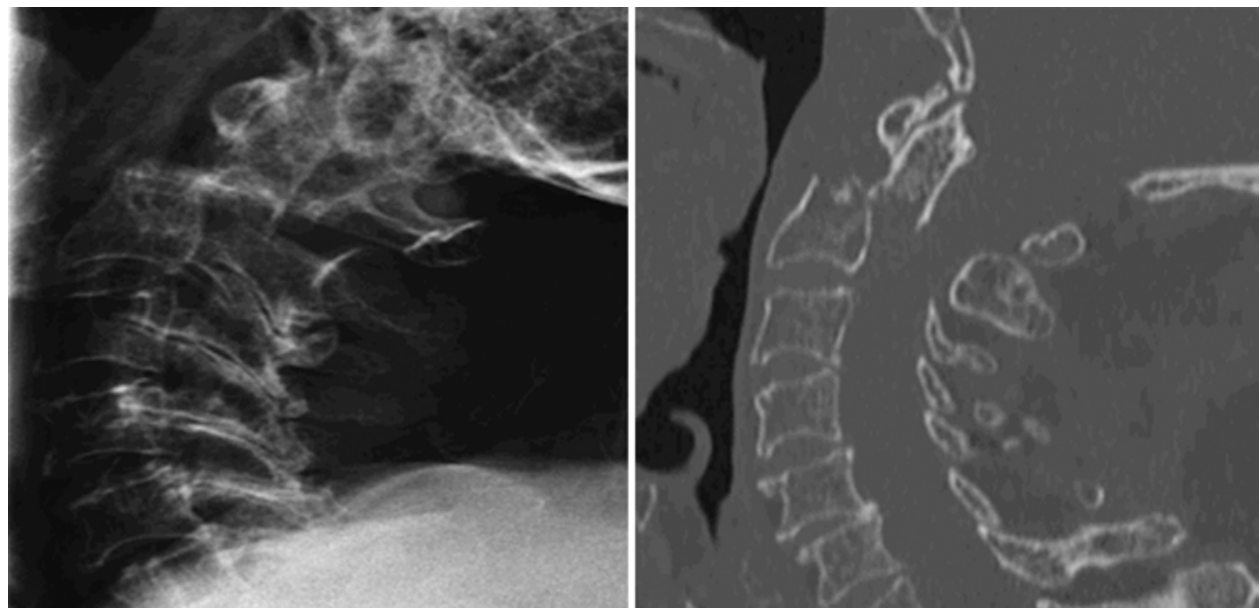

FIG. 4. Case 2. Initial images. Left: Static radiograph, unloaded, showing a Type IIB displaced fracture. Right: Sagittal CT scan of the cervical spine showing the fracture in $\mathrm{C}-2$ with posterior tilt and severe osteopenia, with greater than $50 \%$ lacunae in the trabecular bone at the base of the axis.

but nothing untoward occurred. Additional cement was injected after the leak was detected in the first case but there was no further leakage.

Pain relief was immediate postoperatively in both cases and was maintained at 1 and 3 months, and for the patient in Case 1 at 6 and 12 months. A first-line analgesic was provided for the first 10 days. In Case 1, the SF-36 score remained the same throughout all reviews. No change in the range of motion was noted.

Fortunately, there were no hemorrhagic or infectious complications. The patients were mobilized from Day 1 postoperatively onward. The dynamic radiographs obtained in the immediate postoperative period showed the repair to be perfectly stable (Figs. 6 and 7). This was also

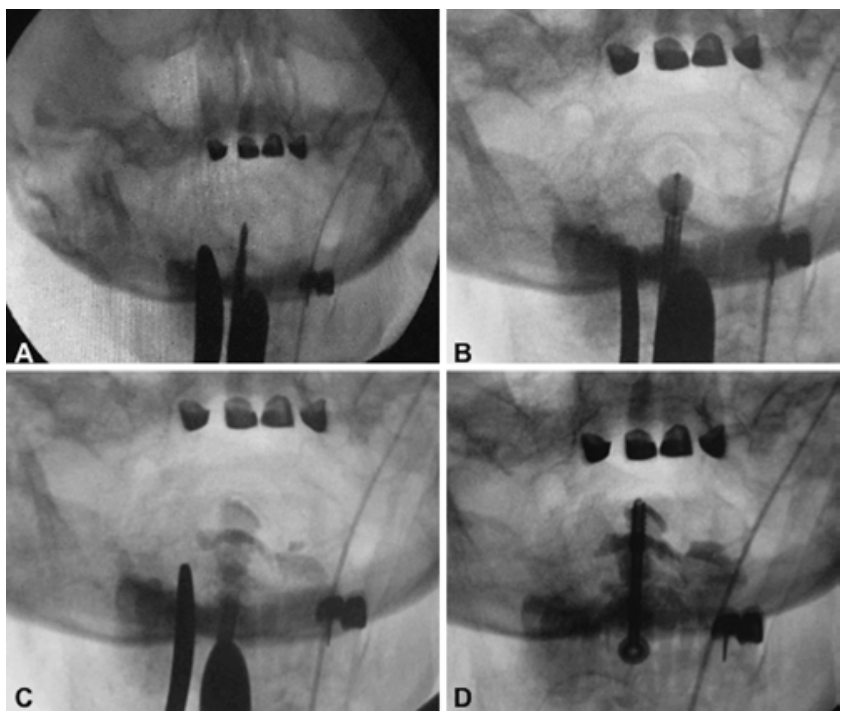

FIG. 5. Intraoperative radiographs. A: Tapping of the body of C-2 and the odontoid above the fracture line. B: The balloon is inflated above the fracture line with preservation of cancellous bone at the apex of the odontoid peg. C: Injection of the high-viscosity cement. Slight lateral leakage is noted at the fracture line. D: Final check with the Asnis screw in place. The entire threaded portion of the screw is above the fracture line. confirmed at various reviews up to 1 year for the patient in Case 1, and up to 3 months for the patient in Case 2 . Computed tomography of the cervical spine confirmed this stability, at 1 month for the 2 patients, as well as at 1 year for the patient in Case 1 .

Inpatient stays were for 3 and 4 days postoperatively. Both patients are still alive.

\section{Discussion}

To our knowledge, we present the first cases in the literature of an innovative treatment combining kyphoplasty and anterior screw fixation performed in 2 approximately 90 -year-old women to treat Type IIB fractures of the odontoid. There is no consensus on the treatment of this type of fracture in the elderly.

Immobilization with a Halo vest system is the most fre-
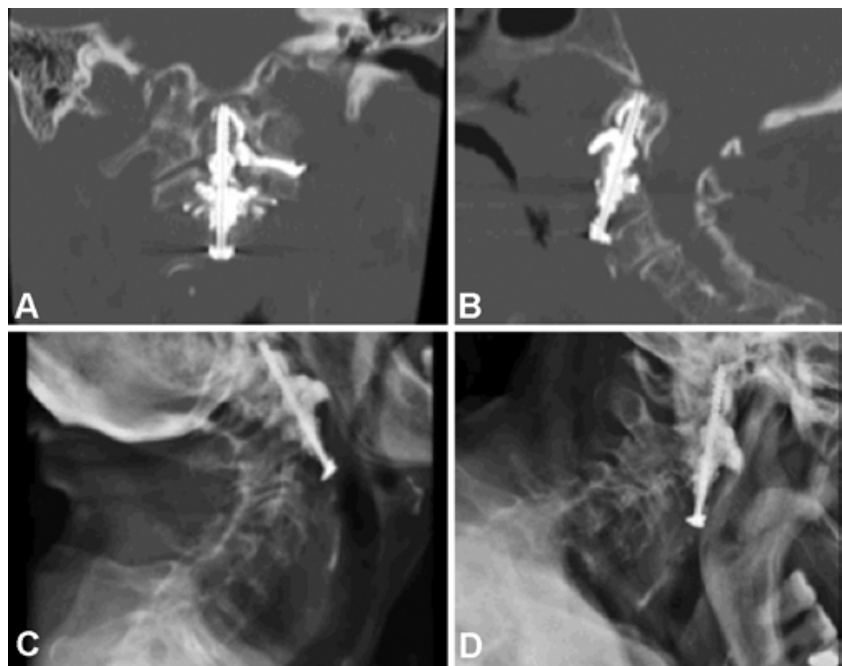

FIG. 6. Case 1. Long-term results. Coronal (A) and sagittal (B) CT scans of the cervical spine obtained 1 year postoperatively. Note the left lateral and anterior leakage; there is no posterior leakage. Dynamic radiographs of the cervical spine in extension (C) and flexion (D) obtained 1 year postoperatively, showing the absence of residual instability. 


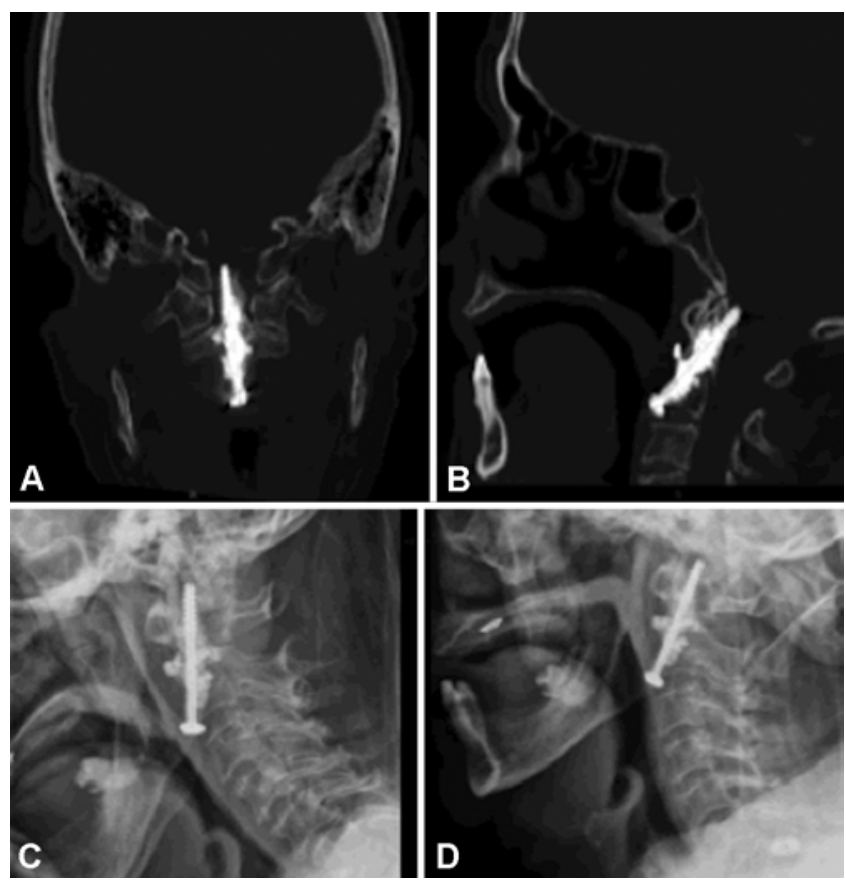

FIG. 7. Case 2. Long-term results. Coronal (A) and sagittal (B) CT scans of the cervical spine obtained 1 month postoperatively. The fracture has been reduced, and there is a slight leak of cement anteriorly. Dynamic flexion (C) and extension (D) radiographs of the neck obtained 1 month postoperatively, showing absence of any remaining instability at the fracture site.

quently described conservative treatment., ${ }^{1,12}$ Numerous studies have described the morbidity associated with this type of treatment, increasing to $66 \%$ for major complications. ${ }^{25,44}$ Other studies have reported treatment with a rigid collar or a soft collar but for Type I or III fractures..$^{29,37}$

Surgical treatments are divided into 2 main categories, posterior fixation and anterior screw fixation of the odontoid. The various techniques for posterior fixation have been described in the review of the literature by Pryputniewicz and Hadley. ${ }^{35}$ Anterior screw fixation of the odontoid has proved to be effective for trauma to the odontoid in all age groups, ${ }^{32}$ but also more specifically for the elderly., 98,19 The most commonly encountered complication is dysphagia, making a nasogastric tube necessary for several weeks as noted in $25 \%$ of the cases in the cohort reported by Dailey et al..$^{9}$ On the other hand, this technique does not limit the range of motion. Rates of fusion are higher in these 2 techniques, ranging from $78 \%$ to $100 \%$ for posterior fixation ${ }^{35}$ and up to $90 \%$ fusion for anterior screw fixation. ${ }^{28}$ Nevertheless, posterior fixations are responsible for a decrease in the range of motion in the neck (notably of rotation) by approximately 50\%. Again, screw procedures carry a risk of damaging the vertebral artery in up to $8.2 \%$ of cases. ${ }^{35}$ These techniques are not devoid of risk in terms of morbidity and mortality in frail individuals. Ardeshiri et al..$^{5}$ reviewed 5 studies, among them their own cohort of patients, describing, more particularly, surgical morbidity and mortality with values from $0 \%$ to $26 \%$ for morbidity and $0 \%$ to $25 \%$ for mortality. Indeed, this pathological condition can have a fatal outcome, as can be found in numerous series in which there is justifica- tion for stabilization, but at times the comorbidities are a barrier to intervention.

Three well-conducted reviews of the literature ${ }^{20,34}$ do not arrive at any endorsement regarding the treatment of choice, orthopedic or surgical, and in terms of surgery, regarding posterior or anterior fixation. The various articles reviewed are all retrospective analyses of small cohorts, with assessment lacking for certain ones, and especially great variation in the evaluation scoring among the series and the follow-up period. What stands out, and only with poor levels of confidence, is that this pathology, in the particular context of the elderly, has a high rate of morbidity and mortality, and notably in relation to each of the particular treatment modalities. Moreover, these can lead to failure with the development of a pseudarthrosis. The meta-analysis carried out by Nourbakhsh et al. ${ }^{33}$ shows, for patients older than 45-55 years of age, a fusion rate of $60 \%$ for the group treated orthopedically (38\%-79\%) compared with $85 \%$ for the group treated surgically (78\%-91\%). Two recent prospective studies are found in the literature.

Konieczny et al. ${ }^{22}$ conducted a prospective analysis of treatments they performed. Their study was not randomized, because the analysis was designed according to an algorithm of their own. Neither the type of fracture nor the age group was specifically examined. The algorithm is based on the stability of the fracture using dynamic radiography criteria, age, and neurological involvement. The stable fractures were all treated orthopedically (in a Philadelphia-type collar); the patients younger than 75 years with unstable fractures were treated by anterior screw fixation. All patients with neurological involvement and all patients with Type III D'Alonzo and Anderson fractures were treated using C1-2 transarticular screws. Even if the rate of fusion in this prospective study is excellent (68 of 69 patients), 5 patients underwent a second surgical procedure, and the algorithm itself is not beyond reproach. Vaccaro et al. ${ }^{45}$ were more specific in their prospective study of functional repercussions and quality of life for Type II fractures in the elderly. The cohort is one of the largest, with 159 patients enrolled, and the study is a multicenter study. The main drawback is the absence of randomization, the choice of treatment being left up to the individual assessment by the surgeon in the different centers. The surgical group had the more favorable outcome according to the 2 scoring systems chosen (Neck Disability Index and SF-36 version 2). There was no significant difference between the 2 groups in terms of complication rates, but the surgical group had a significantly higher rate of fusion $(95 \%$ vs $79 \%)$. The mortality rate was higher in the nonsurgical group, but the difference was not significant.

When comorbidities do not cloud the surgical prognosis, it would seem that this treatment might be the most suitable for limiting morbidity and mortality. Nevertheless, in the patients we treated, it did not seem reasonable to proceed with a posterior fixation, because a ventral decubitus operating position was necessary, and because of the increased risk of infection and the necessarily longer operating time. This option has been reported for a patient 98 years of age. ${ }^{42}$ However, the skin complications linked to the orthosis in Case 1 and the posterior displacement of 
the fragment in Case 2 made the surgical choice inevitable for us. The associated comorbidities, and, in particular the osteopenia, put us in fear of odontoid pseudarthrosis after screw placement, since old age and osteoporosis are the 2 factors most associated with nonfusion in this surgical procedure.

Several cases of vertebroplasty have been reported, the aim being to optimize stability and reduce pain in lytic lesions in the body of C-2.,43 There was just one report in which the fracture did not heal and the pain persisted. ${ }^{4} \mathrm{~A}$ surgical approach similar to that of odontoid screw fixation was followed in 1 case. ${ }^{8}$ Kyphoplasty alone has also been described in 7 cases for painful lytic lesions, either metastases or of myelomatous origin. ${ }^{11,14,15,26,31}$ This method allows for preferential determination of placing the cement and thus limiting the risks of leakage. The surgical approach allows for control over the vascular bundles, and the anterolateral cervical approach limits the risks of infection, such as those associated with the transoral approach. ${ }^{30}$

Dysphagia is often a major concern in this procedure. The major step is the duration of the surgery and especially the stretching time imposed on the aerodigestive tract. The total stretching time was less than 15 minutes for these 2 cases because we relaxed the retraction when the spacing was not necessary. Second, we prophylactically administered corticosteroids to prevent edema (1 mg/ $\mathrm{kg} / \mathrm{day}$ ) for 2 days postoperatively. With these 2 steps, we did not observe dysphagia in these cases.

The addition of cement to anterior screw fixation of the odontoid seems manageable, with an obvious advantage from the consolidation. A single case of vertebroplasty combined with odontoid screw fixation has been reported..$^{41}$ It seems preferable to us to optimize the position of the cement above and below the fracture line by carrying out a kyphoplasty. A 20-mm balloon deployed above and below the fracture line and inflated just once seems to be the best option.

To summarize, we suggest anterior surgery for a Type IIB dens fracture in elderly patients in the following cases: the posterior displacement is more than $4 \mathrm{~mm}$, the $\mathrm{Mi}$ nerva corset is not borne by the patient, and an increase in the displacement is found despite the Minerva corset.

We recommend kyphoplasty when the CT scan highlights osteopenia. A prospective study comparing immobilization with Minerva corset, single anterior screw, and the association of anterior screwing and kyphoplasty should allow us to confirm or reject this potential recommendation.

\section{Conclusions}

To optimize the healing of Type IIB fractures in patients who are approximately 90 years old, we propose an innovative and quick surgical technique that combines anterior screw fixation of the odontoid with kyphoplasty. This allowed for a prompt return to self-sufficiency in frail patients with, in both cases, no complications and a stable structural outcome, and also with only mild adverse effects immediately postoperatively. This technique permits avoidance of the morbidity associated with orthopedic treatments and posterior fixation, and, at the same time, reduces the risk of pseudarthrosis as linked to simple screw fixation, the incidence of which is directly related to osteopenia and advanced age.

\section{References}

1. Aldrian S, Erhart J, Schuster R, Wernhart S, Domaszewski F, Ostermann R, et al: Surgical vs nonoperative treatment of Hadley type IIA odontoid fractures. Neurosurgery 70:676683,2012

2. Anderson LD, D'Alonzo RT: Fractures of the odontoid process of the axis. J Bone Joint Surg Am 56:1663-1674, 1974

3. Anselmetti GC, Manca A, Montemurro F, Tutton S, Chiara G, Battistella M, et al: Vertebroplasty using transoral approach in painful malignant involvement of the second cervical vertebra (C2): a single-institution series of 25 patients. Pain Physician 15:35-42, 2012

4. Anselmetti GC, Regge D, Sardo E, Manca A, Cirillo S, Meloni T, et al: Minimally invasive treatment of C2 odontoid traumatic fracture with transoral percutaneous vertebroplasty. Eur Radiol 17:850-851, 2007

5. Ardeshiri A, Asgari S, Lemonas E, Oezkan N, Schlamann M, Sure U, et al: Elderly patients are at increased risk for mortality undergoing surgical repair of dens fractures. Clin Neurol Neurosurg 115:2056-2061, 2013

6. Böhler J: [Screw-osteosynthesis of fractures of the dens axis (author's transl).] Unfallheilkunde 84:221-223, 1981 (Ger)

7. Clark CR, White AA III: Fractures of the dens. A multicenter study. J Bone Joint Surg Am 67:1340-1348, 1985

8. Cohen M, Zeitoun D, Blanpain S, Brochard C, Lellouche J, Deramond $\mathrm{H}$ : Percutaneous vertebroplasty of the $\mathrm{C} 2$ body and dens using the anterior oblique ascending transdiscal approach. J Neuroradiol 40:211-215, 2013

9. Dailey AT, Hart D, Finn MA, Schmidt MH, Apfelbaum RI: Anterior fixation of odontoid fractures in an elderly population. J Neurosurg Spine 12:1-8, 2010

10. Dang D, Baig MN, Christoforidis G, Chiocca EA, Gabriel J: C2/C3 pathologic fractures from polyostotic fibrous dysplasia of the cervical spine treated with percutaneous vertebroplasty. Eur Spine J 16 (Suppl 3):250-254, 2007

11. Druschel C, Schaser KD, Melcher I, Haas NP, Disch AC: Minimally invasive combined anterior kyphoplasty for osteolytic C2 and C5 metastases. Arch Orthop Trauma Surg 131:977-981, 2011

12. Dunn ME, Seljeskog EL: Experience in the management of odontoid process injuries: an analysis of 128 cases. Neurosurgery 18:306-310, 1986

13. Elgafy H, Dvorak MF, Vaccaro AR, Ebraheim N: Treatment of displaced type II odontoid fractures in elderly patients. Am J Orthop 38:410-416, 2009

14. Fransen P, Collignon FP: Direct anterolateral balloon kyphoplasty for a painful C-2 osteolytic malignant lesion. Case illustration. J Neurosurg Spine 6:374, 2007

15. Fuentes S, Métellus P, Pech-Gourg G, Dufour H, Grisoli F: [Surgical kyphoplasty for management of axis metastasis: technical note kyphoplastie de C2.] Neurochirurgie 55:323327, 2009 (Fr)

16. Grauer JN, Shafi B, Hilibrand AS, Harrop JS, Kwon BK, Beiner JM, et al: Proposal of a modified, treatment-oriented classification of odontoid fractures. Spine J 5:123-129, 2005

17. Hadley MN, Browner CM, Liu SS, Sonntag VKH: New subtype of acute odontoid fractures (type IIA). Neurosurgery 22:67-71, 1988

18. Harrop JS, Przybylski GJ, Vaccaro AR, Yalamanchili K: Efficacy of anterior odontoid screw fixation in elderly patients with Type II odontoid fractures. Neurosurg Focus 8(6):E6, 2000

19. Hénaux PL, Cueff F, Diabira S, Riffaud L, Hamlat A, Brassi- 
er G, et al: Anterior screw fixation of type IIB odontoid fractures in octogenarians. Eur Spine J 21:335-339, 2012

20. Huybregts JGJ, Jacobs WCH, Vleggeert-Lankamp CLM: The optimal treatment of type II and III odontoid fractures in the elderly: a systematic review. Eur Spine J 22:1-13, 2013

21. Koivikko MP, Kiuru MJ, Koskinen SK: Occurrence of comminution (type IIA) in type II odontoid process fractures: a multi-slice CT study. Emerg Radiol 10:84-86, 2003

22. Konieczny MR, Gstrein A, Müller EJ: Treatment algorithm for dens fractures: non-halo immobilization, anterior screw fixation, or posterior transarticular C1-C2 fixation. J Bone Joint Surg Am 94:e144,, 2012

23. Lakshmanan P, Jones A, Howes J, Lyons K: CT evaluation of the pattern of odontoid fractures in the elderly-relationship to upper cervical spine osteoarthritis. Eur Spine J 14:78-83, 2005

24. Lennarson PJ, Mostafavi H, Traynelis VC, Walters BC: Management of type II dens fractures: a case-control study. Spine (Phila Pa 1976) 25:1234-1237, 2000

25. Lind B, Bake B, Lundqvist C, Nordwall A: Influence of halo vest treatment on vital capacity. Spine (Phila Pa 1976) 12:449-452, 1987

26. Lykomitros V, Anagnostidis KS, Alzeer Z, Kapetanos GA: Percutaneous anterolateral balloon kyphoplasty for metastatic lytic lesions of the cervical spine. Eur Spine J 19:19481952,2010

27. Martin JB, Gailloud P, Dietrich PY, Luciani ME, Somon T, Sappino PA, et al: Direct transoral approach to C2 for percutaneous vertebroplasty. Cardiovasc Intervent Radiol 25:517-519, 2002

28. McCullen GM, Garfin SR: Spine update: cervical spine internal fixation using screw and screw-plate constructs. Spine (Phila Pa 1976) 25:643-652, 2000

29. Molinari RW, Khera OA, Gruhn WL, McAssey RW: Rigid cervical collar treatment for geriatric type II odontoid fractures. Eur Spine J 21:855-862, 2012

30. Mont'Alverne F, Vallée JN, Cormier E, Guillevin R, Barragan $\mathrm{H}$, Jean $\mathrm{B}$, et al: Percutaneous vertebroplasty for metastatic involvement of the axis. AJNR Am J Neuroradiol 26:1641-1645, 2005

31. Monterumici DAF, Narne S, Nena U, Sinigaglia R: Transoral kyphoplasty for tumors in C2. Spine J 7:666-670, 2007

32. Morandi X, Hanna A, Hamlat A, Brassier G: Anterior screw fixation of odontoid fractures. Surg Neurol 51:236-240, 1999

33. Nourbakhsh A, Shi R, Vannemreddy P, Nanda A: Operative versus nonoperative management of acute odontoid Type II fractures: a meta-analysis. J Neurosurg Spine 11:651-658, 2009

34. Pal D, Sell P, Grevitt M: Type II odontoid fractures in the elderly: an evidence-based narrative review of management. Eur Spine J 20:195-204, 2011

35. Pryputniewicz DM, Hadley MN: Axis fractures. Neurosurgery 66 (3 Suppl):68-82, 2010

36. Reddy AS, Dinobile D, Orgeta JE, Peri N: Transoral approach to CT-guided C2 interventions. Pain Physician 12:253-258, 2009

37. Rizk E, Kelleher JP, Zalatimo O, Reiter T, Harbaugh R, McInerney J, et al: Nonoperative management of odontoid fractures: a review of 59 cases. Clin Neurol Neurosurg 115:1653-1656, 2013
38. Rodriguez-Catarino M, Blimark C, Willén J, Mellqvist UH, Rödjer S: Percutaneous vertebroplasty at C2: case report of a patient with multiple myeloma and a literature review. Eur Spine J 16 (Suppl 3):242-249, 2007

39. Roy-Camille R, Saillant G, Judet T, de Botton G, Michel G: [Factors of severity in the fractures of the odontoid process (author's transl).] Rev Chir Orthop Reparatrice Appar Mot 66:183-186, 1980 (Fr)

40. Sachs DC, Inamasu J, Mendel EE, Guiot BH: Transoral vertebroplasty for renal cell metastasis involving the axis: case report. Spine (Phila Pa 1976) 31:E925-E928, 2006

41. Scholz M, Schnake KJ, Hoffmann R, Kandziora F: [Cementaugmented anterior odontoid screw fixation of a AndersonD'Alonzo type II fracture with massive osteoporosis. Case report.] Z Orthop Unfall 149:308-311, 2011 (Ger)

42. Siu TL: Type II odontoid fracture in a nonagenarian. J Am Geriatr Soc 60:381-382, 2012

43. Sun G, Wang LJ, Jin P, Liu XW, Li M: Vertebroplasty for treatment of osteolytic metastases at $\mathrm{C} 2$ using an anterolateral approach. Pain Physician 16:E427-E434, 2013

44. Tashjian RZ, Majercik S, Biffl WL, Palumbo MA, Cioffi WG: Halo-vest immobilization increases early morbidity and mortality in elderly odontoid fractures. J Trauma 60:199203, 2006

45. Vaccaro AR, Kepler CK, Kopjar B, Chapman J, Shaffrey C, Arnold P, et al: Functional and quality-of-life outcomes in geriatric patients with type-II dens fracture. J Bone Joint Surg Am 95:729-735, 2013

46. Vetel JM, Leroux R, Ducoudray JM: [AGGIR. Practical use. Geriatric Autonomy Group Resources Needs.] Soins Gerontol 13:23-27, 1998 (Fr)

47. Ware JE Jr, Sherbourne CD: The MOS 36-item short-form health survey (SF-36). I. Conceptual framework and item selection. Med Care 30:473-483, 1992

48. Watanabe M, Sakai D, Yamamoto Y, Sato M, Mochida J: Upper cervical spine injuries: age-specific clinical features. J Orthop Sci 15:485-492, 2010

49. Yoon JY, Kim TK, Kim KH: Anterolateral percutaneous vertebroplasty at $\mathrm{C} 2$ for lung cancer metastasis and upper cervical facet joint block. Clin J Pain 24:641-646, 2008

\section{Author Contributions}

Conception and design: Buffenoir. Acquisition of data: Buffenoir, Terreaux, Loubersac. Analysis and interpretation of data: Buffenoir, Terreaux, Hamel. Drafting the article: Buffenoir, Terreaux, Loubersac, Bord, Robert. Critically revising the article: all authors. Reviewed submitted version of manuscript: all authors. Approved the final version of the manuscript on behalf of all authors: Buffenoir. Study supervision: Buffenoir.

\section{Correspondence}

Kevin Buffenoir, Department of Neurosurgery and Neurotraumatology, Hôtel Dieu University Hospital, 1 Place Alexis Ricordeau, 44093 Nantes, France. email: kevin.buffenoirbillet@ chu-nantes.fr. 